\title{
Woman's needs and satisfaction regarding the communication with doctors and midwives during labour, delivery and early postpartum
}

\author{
Barbara Baranowska ${ }^{1}$, Paulina Pawlicka ${ }^{2 *}$, Iwona Kiersnowska ${ }^{3}$, Alicja Misztal ${ }^{4}$, Anna Kajdy 5 , \\ Dorota Sys ${ }^{5}$ and Antonina Doroszewska ${ }^{6}$ \\ 1 Department of Midwifery, Centre of Postgraduate Medical Education, Warsaw, Poland; \\ barbara.baranowska@cmkp.edu.pl \\ 2 Institute of Psychology, University of Gdansk, Poland; paulina.pawlicka@ug.edu.pl \\ 3 Department of Obstetrics and Perinatology, Medical University of Warsaw, Warsaw, Poland; \\ ikiersnowska@gmail.com \\ 4 St. Sophia's Specialist Hospital, Warsaw, Poland; alicja.misztal@gmail.com \\ 5 Department of Reproductive Health, Centre of Postgraduate Medical Education, Warsaw, Poland; \\ akajdy@cmkp.edu.pl (A.K.); dsys@cmkp.edu.pl (D.S.) \\ 6 Department of Medical Communication, Medical University of Warsaw, Poland; skm@wum.edu.pl \\ * Correspondence: paulina.pawlicka@ug.edu.pl; Tel.: +48 790534566
}

\begin{abstract}
The study aims to identify the difference in communication needs of women giving birth and women during puerperium. An additional goal includes the analysis of the experience and communication needs through the context of a woman's approach to childbirth. The study is a prospective, cross-sectional, self-report survey. 521 women between 5 and 10 days after birth participated in the study. Women perceived information provided by the medical staff as the most helpful aspect of verbal communication both during labour and puerperium. Maintaining eye contact with the medical staff was perceived as the most helpful aspect of non-verbal communication. Women were more satisfied with communication during labour and birth than in the maternity ward and those after non-instrumental childbirth were more satisfied with communication compared to the instrumental birth group. Women perceiving childbirth as the natural, physiological process considered verbal and non-verbal communication during and after childbirth as less helpful than women perceiving birth as more risky and requiring interventions. The results of the study emphasize the importance of verbal and non-verbal communication during birth and puerperium and different communication needs during labour and early postpartum. It also showed that women who perceive labour as a physiological process seem to be less dependent on the communication with the medical staff than women who accept medical interventions during labour and birth as necessary.
\end{abstract}

Keywords: communication; childbirth; satisfaction; quality of care

\section{Introduction}

Communication constitutes one of the eight domains of the quality of the perinatal care within the framework proposed by the World Health Organization [1]. The rapport between the woman and the midwife is largely built through communication [2,3]. Communication may become the element strengthening the feeling of safety and self-efficacy of the birthing woman, which is vital during labour and significantly affects the woman's satisfaction with the perinatal care [2,4]. According to Hunter, "the quality of relationships is inevitably linked to the quality of communication, and effective communication is essential for safe practice."[5] With regard to the perinatal care it is emphasized that 'communication with women and their families is effective and responds to their needs and preferences' (Standard 4, WHO, 2016) [6]. At the same time, no agreement has been 
reached with regard to the definition of an effective communication in the perinatal care $[7,8]$. The qualitative research conducted by Downe team describes the needs of the women in labour and their expectations towards maternity and perinatal care, which to a large extent pertain to the way of communication with the staff [9]. The research results show that providing the information in a clear manner and the staff's interest in women's needs and fears, are of key importance for these women. This is primarily reflected in the staff being able to listen to what the woman says during labour [10].

The studies dedicated to the communication between the maternity care staff and women are mainly aimed at the effectiveness of perfecting the communication skills $[7,11,12]$. Secondly they aim at lowering the barriers to the facility-based delivery in low- and middle-income countries $[13,14]$. They most commonly are therefore presented in the context of providing patients with respectful care $[15,16]$. The most investigated communication skills include active listening, giving information, and obtaining an informed consent [8].

Non-verbal communication is one of the key communication skills in the midwife's work. According to The Nursing and Midwifery Council's Code, the midwife should "use a range of verbal and non-verbal communication methods, and consider cultural sensitivities, to better understand and respond to people's personal and health needs."[17] The research on communication skills of midwives indicate a relationship between women's satisfaction and with midwives' both verbal and non-verbal communication skills [18]. The same study showed that the midwives achieved a higher level of the verbal than the non-verbal communicative behaviours [18].

During a natural childbirth, the woman's body withdraws from cognitive processes. An instinctive action related to the secretion of hormones dominates her behaviour. However, in the postpartum period, the woman's attention is focused on the child and the search for information and assistance in a proper taking care of the baby. This different nature of tasks and activities during the childbirth and puerperium may be associated with different needs for verbal and non-verbal methods of communication with the medical staff. Women's experience contributing to the final assessment of satisfaction with the care received at the hospital may be divided into the experience before labour (usually at the admission), during labour (in the labour room) and after labour (in the maternity ward). The results of previous studies point to differences in the women's feelings related to their stay at the given hospital unit [19].

The aim of the present study was to verify if there are differences in the needs of the women in labour and puerperium related to the verbal and non-verbal communication with the medical staff. Secondly we wanted to assess if these needs are differentiated by the perception of the risk of childbirth for the mother and the baby. Thirdly, we wanted to analyse the possible differences in the communication needs with regards to the instrumentalization of delivery.

\section{Materials and Methods}

In this cross-sectional, descriptive study, a survey was administered to 521 women from two hospitals (a hospital clinic and a hospital with a birth centre) in Warsaw, Poland. The recruitment rate was $95 \%$. Participants filled in the paper-and-pencil self-administered questionnaire directly before the discharge from the hospital (5-10 days after labour). The survey was conducted in Polish. Content validation for the questions concerning the communication needs and the one regarding perception of childbirth was performed by the expert panel including three midwives, two psychologists and one obstetrician. In the validation process, the questionnaire received the following value $\mathrm{S}-\mathrm{CVI}=0,80$. The coefficients of reliability were Cronbach's alpha $=0.71$. The study was anonymous, and the participation was voluntary. All participants expressed their consent to take part in the study.

\subsection{Communication needs and satisfaction with communication during birth and early postpartum}

The survey included questions about women's needs for verbal and non-verbal communication with the medical staff during childbirth and in the maternity ward. Four questions related to this aspect with regards to the experience during birth and the same questions were asked with regards to the postpartum experience. The instruction was as follows: 'Please imagine or recall the birthing 
experience and indicate whether during birth/ Please imagine or recall the postpartum experience and indicate whether in the maternity ward: 1) Asking a large number of questions by doctors/ midwives; 2) Maintaining eye contact with the midwife; 3) Receiving a large amount of information from the doctor/midwife; 4) Communicating with the midwife by touch'. Then participants were asked to mark one of three possibilities of answer to each question: 1: disturbed me; 2: had no impact; 3: helped me.

Two additional questions regarding the satisfaction from the received care during birth ('Please, mark your level of satisfaction with the communication with the medical staff during your stay in the hospital during labour and birth') and early postpartum ('Please, mark your level of satisfaction with the communication with the medical staff during your stay in the hospital maternity ward') were included in the survey. Participants responded on a 5-point Likert scale from 1 (definitely not satisfied) to 5 (definitely satisfied).

\subsection{Perception of the childbirth risk}

Perception of the childbirth risk was assessed with one question: 'Please, mark one answer that best reflects your opinion about the childbirth' with 3 possibilities provided: 1) Woman is capable of giving birth to a child and usually no medical intervention is needed; 2) Childbirth is a normal physiological process, but medical interventions are necessary to carry out the birth and give birth to a healthy child; 3) Childbirth is always at high risk for the baby and the mother. Thus study participants were divided into three groups according to the marked option: women who perceive childbirth as an instinctive process (the physiology group), women who believe that medical interventions are necessary for the birth of a healthy child (the intervention acceptance group) and women for whom childbirth is a high-risk event not only for the mother but also for the child (the high-risk group).

\subsection{Other descriptive variables}

The questions about demographic characteristics were included in the survey (age, education level, marital status, parity) and the factors which could significantly impact the feelings of connection with labour and birth: mode of delivery, epidural use, presence of a birth partner, place of birth (birth centre or standard delivery ward), interventions - labour induction or augmentation. We have differentiated the group of women who experienced an instrumental delivery (caesarean section or vaginal birth with use of vacuum or forceps) and the group of women after the noninstrumental delivery (vaginal birth with or without medications).

\subsection{Statistical analysis}

The data obtained from the study were analysed using the SPSS 26.0 package software. Frequency, percentage, and Pearson correlation coefficient were calculated. In addition, student dependent and independent t-test and the analysis of variance (one-way ANOVA) with post-hoc Tukey test were performed in order to validate the research questions.

The study received the approval of the Ethics Committee at the Medical University of Warsaw, ref. no. AKBE/232/2017.

\section{Results}

\subsection{Characteristics of the study group}

521 women (75.3\% aged between 26 and 35 years; 85.5\% with higher education) participated in the study. $96.5 \%$ gave birth in the maternity wards in public hospitals in Warsaw, Poland and 3.5\% (18 women) in the birth centre. 52\% were primiparas; $69 \%$ had vaginal birth (16.2\% had unmedicated vaginal birth and $53.2 \%$ medicated with epidural, Entonox and/or oxytocin induction). $14.3 \%$ had 
planned and $16.4 \%$ unplanned c-section. $72 \%$ of women had a close person accompanying them during labour and/or birth.

\subsection{Communication needs during childbirth/ early postpartum and satisfaction with communication}

Both verbal (providing information, asking questions) and non-verbal (touching, maintaining eye contact) communication with the medical staff was perceived as helpful during childbirth and in the maternity ward. However, women differently assessed the same aspects of communication in these two situations (Table 1). Verbal communication was more often assessed as helpful in the maternity ward than during labour and birth. The same pertains to maintaining the eye contact with the midwife. However, being touched was more often marked as helpful during labour and birth than in the maternity ward. Within the verbal communication, providing information was more often perceived as helpful than asking questions, and within the non-verbal communication maintaining the eye contact was more helpful than being touched (Table 1).

General satisfaction with communication with the medical staff was high both during labour: 4,74 (SD=.565; scale 1-5) and early postpartum: 4,58 (SD=.665; scale 1-5) (Table 1). However, women were more satisfied with communication during labour and birth than in the maternity ward.

Table 1. Descriptive statistics and results of the dependent t-test analysis of communication needs and communication satisfaction during childbirth and early postpartum.

\begin{tabular}{|c|c|c|c|c|c|c|}
\hline $\begin{array}{c}\text { Communication } \\
\text { aspect }\end{array}$ & $N$ & $M$ & $S D$ & $t$ & $d f$ & $p$ \\
\hline questions -birth & 518 & 2.18 & .766 & \multirow[b]{2}{*}{-9.245} & \multirow[b]{2}{*}{517} & \multirow[b]{2}{*}{.000} \\
\hline $\begin{array}{c}\text { questions -birth } \\
\text { questions - } \\
\text { postpartum }\end{array}$ & 518 & 2.50 & .733 & & & \\
\hline $\begin{array}{l}\text { information - } \\
\text { birth }\end{array}$ & 516 & 2.79 & .502 & \multirow[t]{2}{*}{-4.792} & \multirow[t]{2}{*}{515} & \multirow[t]{2}{*}{.000} \\
\hline $\begin{array}{l}\text { information- } \\
\text { postpartum }\end{array}$ & 516 & 2.88 & .361 & & & \\
\hline $\begin{array}{l}\text { eye contact - } \\
\text { birth }\end{array}$ & 515 & 2.72 & .490 & \multirow{2}{*}{-3.712} & \multirow{2}{*}{514} & \multirow{2}{*}{.000} \\
\hline $\begin{array}{l}\text { eye contact- } \\
\text { postpartum }\end{array}$ & 515 & 2.80 & .432 & & & \\
\hline touching - birth & 515 & 2.64 & .547 & \multirow{2}{*}{3.751} & \multirow{2}{*}{514} & \multirow{2}{*}{.000} \\
\hline $\begin{array}{l}\text { touching - } \\
\text { postpartum }\end{array}$ & 515 & 2.55 & .553 & & & \\
\hline $\begin{array}{l}\text { satisfaction - } \\
\text { birth }\end{array}$ & 517 & 4.74 & .565 & \multirow[t]{2}{*}{5.216} & \multirow[t]{2}{*}{516} & \multirow[t]{2}{*}{.000} \\
\hline $\begin{array}{l}\text { satisfaction - } \\
\text { postpartum }\end{array}$ & 517 & 4.58 & .665 & & & \\
\hline
\end{tabular}

The communication needs and satisfaction were also analysed with respect to the mode of delivery. The results of the independent $t$-test analysis showed that the only aspect of communication that differentiated the groups was related to asking questions in the maternity ward, perceived as more helpful by the women after non-instrumental birth (Table 2). Significant differences were however found with regards to the satisfaction with communication during labour/delivery and 
early postpartum. Women after the non-instrumental delivery were more satisfied with the communication with the medical staff in both situations.

Table 2. Descriptive statistics and results of the independent t-test analysis of communication needs and communication satisfaction during and after instrumental and non-instrumental delivery.

\begin{tabular}{|c|c|c|c|c|c|c|c|c|c|}
\hline \multirow[b]{2}{*}{$\begin{array}{c}\text { Communication } \\
\text { aspect }\end{array}$} & \multicolumn{3}{|c|}{ Non-instrumental birth } & \multicolumn{3}{|c|}{ Instrumental birth } & \multirow[b]{2}{*}{$t$} & \multirow[b]{2}{*}{$d f$} & \multirow[b]{2}{*}{$p$} \\
\hline & $N$ & $M$ & $S D$ & $N$ & $M$ & $S D$ & & & \\
\hline questions birth & 336 & 2.18 & .754 & 182 & 2.18 & .790 & .045 & 516 & .964 \\
\hline questions postp. & 337 & 2.55 & .693 & 184 & 2.42 & .792 & 1.907 & 519 & .057 \\
\hline information birth & 335 & 2.80 & .478 & 183 & 2.78 & .544 & .456 & 516 & .648 \\
\hline information postp. & 336 & 2.88 & .356 & 183 & 2.89 & .368 & -.040 & 517 & .968 \\
\hline eye contact birth & 335 & 2.71 & .492 & 180 & 2.74 & .486 & -.751 & 513 & .453 \\
\hline eye contact postp. & 337 & 2.81 & .403 & 184 & 2.79 & .483 & .481 & 519 & .631 \\
\hline touching birth & 337 & 2.63 & .553 & 179 & 2.68 & .554 & 1.096 & 514 & .273 \\
\hline touching postp. & 336 & 2.54 & .545 & 183 & 2.58 & .567 & -.740 & 517 & .460 \\
\hline satisfaction - birth & 336 & 4.84 & .409 & 182 & 4.57 & .745 & 5.225 & 516 & .000 \\
\hline satisfaction postp. & 336 & 4.65 & .618 & 183 & 4.43 & .722 & 3.698 & 517 & .000 \\
\hline
\end{tabular}

\subsection{Perception of childbirth risk and communication needs}

Finally, we wanted to verify whether perception of the childbirth risk differentiates the communication needs and satisfaction of the participants during childbirth and in early postpartum. $15,8 \%$ of participating women indicated that in their opinion birth is the physiological process and no interventions are needed; $64,6 \%$ of participants perceived birth as a normal physiological process, but medical interventions are in their opinion necessary to give birth to a healthy child. $18,2 \%$ of women perceived childbirth as a highly risky process for the baby and the mother.

One-way ANOVA was conducted with the perception of childbirth risk as the differentiating variable and on each of the communication aspects as dependent variables (Table 3).

Table 3. Results of the one-way ANOVA analysis with the perception of childbirth risk as the differentiating variable and each of the communication aspects as dependent variables.

\begin{tabular}{ccccc}
$\begin{array}{c}\text { Communication } \\
\text { aspect }\end{array}$ & $\boldsymbol{F}$ & $d f$ & $p$ & $\eta 2$ \\
\hline questions birth & 11.932 & 2 & .000 & 6.712 \\
questions postp. & 8.991 & 2 & .000 & 4.686 \\
$\begin{array}{c}\text { information birth } \\
\text { information } \\
\text { postp. }\end{array}$ & 2.902 & 2 & .056 & .712 \\
\hline
\end{tabular}




\begin{tabular}{ccccc} 
eye contact birth & 1.811 & 2 & .165 & .434 \\
eye contact postp. & 4.479 & 2 & .012 & .826 \\
& & & & \\
touching birth & 5.078 & 2 & .007 & 1.497 \\
touching postp. & 8.703 & 2 & .000 & 2.582 \\
satisfaction - birth & .259 & 2 & .772 & .083 \\
satisfaction postp. & .836 & 2 & .434 & .371 \\
\hline
\end{tabular}

The results of the analysis showed the main effect of perception of childbirth risk for both aspects of verbal communication (the Tukey post-hoc test indicated that women convinced that labour and birth is the physiological process perceived questions asked during labour and in the maternity ward and information provided in the maternity ward as more disturbing than the two other groups and information from the medical staff during labour as more disturbing than the group perceiving birth as the highly risky experience). With regards to the non-verbal communication needs, the main effect was found for touch during childbirth and early postpartum and for the eye contact postpartum (similarly to the verbal communication needs, according to the results of the post-hoc Tukey test women perceiving childbirth as the natural, physiological process considered being touched during and after childbirth as less helpful than the two other groups, and maintaining eye contact with midwives in the maternity room as less helpful than the women perceiving birth as a highly risky process). Perception of childbirth risk did not differentiate the groups when satisfaction with communication with the medical staff both during and after childbirth were analysed.

\section{Discussion}

Our study fill the gap in the knowledge, as identified by the Guideline Development Group (GDG), related to the communication characteristics in the area of perinatal care, which may influence the labour experience [19]. Satisfaction with the communication with the medical staff is important and it constitutes a significant factor influencing the general satisfaction from birth care and can improve women's experience of childbirth $[\mathbf{2 0 , 2 1 ]}$. Lower satisfaction with the communication with the staff may result in lowering of postpartum mood observed during women's stay on the maternity ward. Fatigue, tension, and anxiety may negatively influence the assessment of the staff. Women experience a range of emotional and hormonal changes in the early perinatal period, which results in often expecting of the additional support expressed via communication [22].

Our study shows a very high level of satisfaction with the communication with the staff both during labour and in the maternity ward. The results are in concordance with the data obtained by Adamska et al. from a representative group of Polish women, which concluded that most of the women in labour thought that the staff communicated with them in an appropriate manner during their hospital stay [19]. Similar results were presented in the group of women in the perinatal care in Iran, and in Egypt, where a vast majority were satisfied with respect to the communication with the staff $[23,24]$. Simultaneously, the experience connected with the childbirth is at times more positive in the early period after labour when compared to the one subsequently reported. Research in Denmark and Sweden demonstrate that the measure of satisfaction with labour assessed directly after the labour may be distorted by relief at finishing a period of tenseness and uncertainty

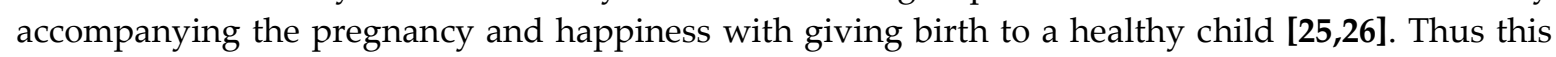
fact should be taken into account when assessing the study results. 
Women indicated receiving information from the staff as the most desired aspect of verbal communication. This applied to communication both in the labour and in the maternity ward. Information obtained from the persons looking after the woman increase her ability to take part in the decision making and by the same token, increase her external control. The increased feeling of external control positively influences the labour experience [27] and allows to make decisions about their childbirth [28]. Women in labour need informational support provided by the staff. 'Offering the woman and her family the information they need in a clear and concise manner' is one of the recommendations regarding effective communication between maternity care providers and women in labour [29]. Feeling informed (about birth process, personnel roles, child's health during birth and about how to feed the child) significantly affects birth experience [30]. In our study verbal communication was more often assessed as helpful in the maternity ward than during labour and birth. It may result from the fact, that the woman in puerperium is focused on receiving messages and information about the baby, so she may prefer the verbal communication, focusing on the newborn, as well as touching and holding him/her. Breastfeeding support and information are also important aspects at this point, affecting both overall birth experience [30] as well as breastfeeding duration [31].

Touching and keeping an eye contact by the medical staff was also perceived as helpful both during labour and early postpartum. However, touch was perceived as more helpful in labour, while maintaining the eye contact was more often indicated as helpful in the maternity ward. According to Penny, 'the touch is a mean of nonverbal communication that is likely to convey a message of involvement with another person, reassurance and concern to the woman in labour" [32] and the midwives themselves consider the touch as a sign of care, acceptance, support, competence, and comfort [33]. The touch during an interaction with the physician affects the positive assessment of the carer's empathy [34]. The touch in labour is also considered as a way of coping with an intense pain [32]. Despite the fact that for most women in labour received touch was helpful because it aided them in coping with the experience, the research shows that not in every labour stage the touch is desired and not every woman perceives it as something comfortable [35]. In many situations, a supportive non-verbal communication instead of directive verbal communication, offered in accordance with the rule 'the less we do, the more we give', may be more beneficial for the labour progress, woman's satisfaction, as well as for the midwives themselves [36].

The lower satisfaction with communication in postpartum than with communication during labour observed in our study may be connected with the change in the system of care after childbirth. In accordance with the national guidelines, the woman in labour has the continuity of care ensured and is taken care of by a single midwife, dedicated to that woman. However, in the maternity ward, one midwife looks after a few or a dozen women and their responsibilities are often related to particular activities (vaccinating, giving bath to children, lactation assistance) rather than looking after a particular woman. Such mode of work influences the time limits during which the staff responds to women's needs, decreases the chance of establishing a rapport with the woman, and may hinder communication. The results of other studies indicate that women tend to assess communication in a more positive way when a smaller number of persons look after them, which in turn gives them a bigger chance to build a rapport and engagement in making decisions regarding the care [8].

The lower satisfaction with communication between women and the staff was observed also in women experiencing the instrumental birth (caesarean section or vaginal with vacuum) compared to women after the non-instrumental one. This may result from the stress experienced by the woman herself, the medical staff focused on efficient performance of the operation or/and lack of time to provide information to a birthing woman. Results of other studies also indicate that particularly women after emergency caesarean sections report lower satisfaction with labour and care during labour [37]. 
Finally, the results of our study emphasize the role of personal attitude towards childbirth in communication needs of birthing women. Majority of participating women stated that medical interventions are necessary to bear a child. The smallest group considered labour and birth as physiological process that does not need medical interventions. However, for these women intensive communication during labour and birth (asking many questions, providing large amount of information and being touched) and in the maternity ward was more disturbing and less helpful than for both other groups. These results may underline their need to experience the birthing process on their own, in their own pace. During labour, the neo-cortex (rational brain) needs to be muted in order to activate the limbic system taking part in an effective secreting of hormones [38]. A conversation and expecting rational responses from the woman in labour may disturb the natural flow of childbirth. Such "immersion" in labour is observed during natural labour [38]. Results of other Polish studies indicate that women childbearing at home (homebirth is usually the natural, physiological birth) report high level of self-efficacy, higher control over pain and more frequent reinterpreting the experience of pain comparing to women giving birth at a hospital indicating their ability and will to be the guides of their birthing process [39]. Yet, as our study showed, in a medicalized, instrumental, or operational labour, the cognitive system is stimulated, so asking questions was perceived as less disturbing for these women.

\section{Conclusions}

The findings of the study underline the importance of the attitude towards childbirth for the communication needs. Women who perceived labour as a physiological process seemed to be less dependent on the communication with the medical staff than women who accepted medical interventions during labour and birth as necessary. It is therefore meaningful to gather information from women about their preferences regarding the means and intensity of communication during childbirth and puerperium and become attentive to changes in their needs according to the context and situation. It is also important to remember about the importance of communication with birthing women during the instrumental delivery, as the results point to the significantly lower satisfaction with care in these situations.

Author Contributions: Conceptualization, B.B., I.K., D.S., and A.D.; methodology, P.P.; software, I.K.; validation, B.B., P.P. and A.K.; formal analysis, P.P.; investigation, A.M.; resources, B.B.; data curation, I.K.; writing-original draft preparation, B.B. and P.P; writing-review and editing, D.S., A.K. A.D.; visualization, I.K.; supervision, D.S, A.K. AD.; project administration, I.K. All authors have read and agreed to the published version of the manuscript.

Funding: This study is supported by the Department of Reproductive Health at Centre of Postgraduate Medical Education Research Program for year 2020.

Conflicts of Interest: The authors declare no conflict of interest.

\section{References}

1. Tunçalp, Özge; Pena-Rosas, J.P.; Lawrie, T.; Bucagu, M.; Oladapo, O.T.; Portela, A.; Metin Gülmezoglu, A. WHO Recommendations on Antenatal Care for a Positive Pregnancy Experience-Going beyond Survival. BJOG: An International Journal of Obstetrics \& Gynaecology 2017, 124, 860-862.

2. Attarha, M.; Keshavarz, Z.; Bakhtiari, M.; Jamilian, M. The Outcome of Midwife-Mother Relationship in Delivery Room: A Qualitative Content Analysis. Health 2016, 08, 336, doi:10.4236/health.2016.84035.

3. Hallam, J.L.; Howard, C.D.; Locke, A.; Thomas, M. Communicating Choice: An Exploration of Mothers' Experiences of Birth. Journal of Reproductive and Infant Psychology 2016, 34, 175-184, doi:10.1080/02646838.2015.1119260. 
4. Freedman, L.P.; Ramsey, K.; Abuya, T.; Bellows, B.; Ndwiga, C.; Warren, C.E.; Kujawski, S.; Moyo, W.; Kruk, M.E.; Mbaruku, G. Defining Disrespect and Abuse of Women in Childbirth: A Research, Policy and Rights Agenda. Bulletin of the World Health Organization 2014, 92, 915-917.

5. Hunter, B.; Berg, M.; Lundgren, I.; Ólafsdóttir, Ó.Á.; Kirkham, M. Relationships: The Hidden Threads in the Tapestry of Maternity Care. Midwifery 2008, 24, 132-137.

6. World Health Organization Standards for Improving Quality of Maternal and Newborn Care in Healthcare Facilities 2016.

7. Chang, Y.-S.; Coxon, K.; Portela, A.G.; Furuta, M.; Bick, D. Interventions to Support Effective Communication between Maternity Care Staff and Women in Labour: A Mixed-Methods Systematic Review. Midwifery 2018, 59, 4-16, doi:10.1016/j.midw.2017.12.014.

8. Rowe, R.E.; Garcia, J.; Macfarlane, A.J.; Davidson, L.L. Improving Communication between Health Professionals and Women in Maternity Care: A Structured Review. Health Expectations 2002, 5, 63-83, doi:10.1046/j.13696513.2002.00159.x.

9. Downe, S.; Finlayson, K.; Oladapo, O.; Bonet, M.; Gülmezoglu, A.M. What Matters to Women during Childbirth: A Systematic Qualitative Review. PloS one 2018, 13, e0194906.

10. Expert Maternity Group; Cumberlege, J.; Great Britain; Department of Health Changing Childbirth. Part 1, Part 1,; HMSO: London, 1993; ISBN 978-0-11-321623-9.

11. Bashour, H.N.; Kanaan, M.; Kharouf, M.H.; Abdulsalam, A.A.; Tabbaa, M.A.; Cheikha, S.A. The Effect of Training Doctors in Communication Skills on Women's Satisfaction with Doctor-Woman Relationship during Labour and Delivery: A Stepped Wedge Cluster Randomised Trial in Damascus. BMJ Open 2013, 3, e002674, doi:10.1136/bmjopen-2013-002674.

12. Crofts, J.F.; Bartlett, C.; Ellis, D.; Winter, C.; Donald, F.; Hunt, L.P.; Draycott, T.J. Patient-Actor Perception of Care: A Comparison of Obstetric Emergency Training Using Manikins and Patient-Actors. BMJ Quality \& Safety 2008, 17, 20-24, doi:10.1136/qshc.2006.021873.

13. Bohren, M.A.; Hunter, E.C.; Munthe-Kaas, H.M.; Souza, J.P.; Vogel, J.P.; Gülmezoglu, A.M. Facilitators and Barriers to Facility-Based Delivery in Low- and Middle-Income Countries: A Qualitative Evidence Synthesis. Reprod Health 2014, 11, 71, doi:10.1186/1742-4755-11-71.

14. Vafaei, Z.; Javadnoori, M.; Najar, S.; Latifi, S.M. Barriers of Effective Communication between Midwives and Parturient Women in Hospitals of Khuzestan Province, Iran, 2012. The Iranian Journal of Obstetrics, Gynecology and Infertility 2013, 15, 10-15.

15. Shakibazadeh, E.; Namadian, M.; Bohren, M.A.; Vogel, J.P.; Rashidian, A.; Nogueira Pileggi, V.; Madeira, S.; Leathersich, S.; Tunçalp, Ö.; Oladapo, O.T. Respectful Care during Childbirth in Health Facilities Globally: A Qualitative Evidence Synthesis. BJOG: An International Journal of Obstetrics \& Gynaecology 2018, 125, 932-942.

16. Vogel, J.P. Promoting Respect and Preventing Mistreatment during Childbirth. BJOG 2016, 123, doi:10.1111/14710528.13750 .

17. Nursing and Midwifery Council The Code: Professional Standards of Practice and Behaviour for Nurses and Midwives. 2015.

18. Taghizadeh, Z.; Rezaiepour, A.; Mehran, A.; Alimoradi, Z. Usage of Communication Skills by Midwives and Its Relation to Clients' Satisfaction. Journal of hayat 2007, 12, 47-55.

19. Adamska-Sala, I.; Baranowska, B.; Doroszewska, A.; Piekarek, M.; Pietrusiewicz, J. Raport z Monitoringu Oddziałów Położniczych. Opieka Okołoporodowa w Polsce w Świetle Doświadczeń Kobiet; Fundacja Rodzić po Ludzku: Warszawa, 2018; ISBN 978-83-60971-29-1. 
20. Nilsson, L.; Thorsell, T.; Hertfelt Wahn, E.; Ekström, A. Factors Influencing Positive Birth Experiences of FirstTime Mothers Available online: https://www.hindawi.com/journals/nrp/2013/349124/ (accessed on 9 November 2020).

21. Ojelade, O.A.; Titiloye, M.A.; Bohren, M.A.; Olutayo, A.O.; Olalere, A.A.; Akintan, A.; Oladapo, O.T.; Fawole, B. The Communication and Emotional Support Needs to Improve Women's Experience of Childbirth Care in Health Facilities in Southwest Nigeria: A Qualitative Study. International Journal of Gynecology \& Obstetrics 2017, 139, 27-37, doi:https://doi.org/10.1002/ijgo.12380.

22. Burns, E.; Fenwick, J.; Sheehan, A.; Schmied, V. Mining for Liquid Gold: Midwifery Language and Practices Associated with Early Breastfeeding Support. Maternal \& Child Nutrition 2013, 9, 57-73, doi:10.1111/j.17408709.2011.00397.x.

23. Katebi, M.S.; Khadivzadeh, T.; Sepehri Shamloo, Z.; Esmaily, H. Evaluating Midwives Communication Skills from the Perspective of Pregnant Women Presenting to Hospitals for Delivery. JMRH 2017, 5, doi:10.22038/jmrh.2016.8019.

24. Sayed, W.; ElAal, D.E.M.A.; Mohammed, H.S.; Abbas, A.M.; Zahran, K.M. Maternal Satisfaction with Delivery Services at Tertiary University Hospital in Upper Egypt, Is It Actually Satisfying? International Journal of Reproduction, Contraception, Obstetrics and Gynecology 2018, 7, 2547-2552, doi:10.18203/23201770.ijrcog20182859.

25. Waldenström, U. Why Do Some Women Change Their Opinion about Childbirth over Time? Birth 2004, 31, 102107, doi:10.1111/j.0730-7659.2004.00287.x.

26. Maimburg, R.D. er; Vla eth, M.; Dahlen, H. Women's Experience of Childbirth-A Five Year Follow-up of the Randomised Controlled Trial "Ready for Child Trial." Women and Birth 2016, 29, 450-454.

27. Hardin, A.M.; Buckner, E.B. Characteristics of a Positive Experience for Women Who Have Unmedicated Childbirth. J Perinat Educ 2004, 10-16, doi:10.1624/105812404X6180.

28. Thachuk, A. Midwifery, Informed Choice, and Reproductive Autonomy: A Relational Approach. Feminism and Psychology 2007, 17, 39-56.

29. WHO Reproductive Health Library WHO Recommendation on Effective Communication between Maternity Care Providers and Women in Labour. 2018.

30. Baranowska, B.; Kajdy, A.; Pawlicka, P.; Pokropek, E.; Rabijewski, M.; Sys, D.; Pokropek, A. What Are the Critical Elements of Satisfaction and Experience in Labor and Childbirth-A Cross-Sectional Study. Int J Environ Res Public Health 2020, 17, doi:10.3390/ijerph17249295.

31. Kiełbratowska, B.; Michałek-Kwiecień, J.; Kaźmierczak, M.; Bandurska, E. What Promotes and Hinders Success in Breastfeeding in Hospital Care? - The Role of Social Support and Anxiety. Health Psychology Report 2018, 6, 252260, doi:10.5114/hpr.2018.73051.

32. Penny, K.S. Postpartum Perceptions of Touch Received during Labor. Res Nurs Health 1979, 2, 9-16, doi:10.1002/nur.4770020103.

33. Weaver, D.F. Nurses' Views on the Meaning of Touch in Obstetrical Nursing Practice. J Obstet Gynecol Neonatal Nurs 1990, 19, 157-161, doi:10.1111/j.1552-6909.1990.tb01634.x.

34. Alimoradi, Z.; Taghizadeh, Z.; Rezaypour, A.; Mehran, A. Evaluation of Midwives' Communication Skills. African Journal of Midwifery and Women's Health 2013, 7, 19-24.

35. Birch, E.R. THE EXPERIENCE OF TOUCH RECEIVED DURING LABOR: Postpartum Perceptions of Therapeutic Value*. Journal of Nurse-Midwifery 1986, 31, 270-275, doi:https://doi.org/10.1016/00912182(86)90036-4. 
36. Pakgohar, M.; Rahimikian, F.; Mehran, A.; Mohammadi, T. Quality Assessment of Family Planning Counseling in Health and Treatment Centers, Affiliated to Tehran University of Medical Sciences. Journal of hayat 2002, 8, 6271.

37. Alderdice, F.; Henderson, J.; Opondo, C.; Lobel, M.; Quigley, M.; Redshaw, M. Psychosocial Factors That Mediate the Association between Mode of Birth and Maternal Postnatal Adjustment: Findings from a Population-Based Survey. BMC Womens Health 2019, 19, 42, doi:10.1186/s12905-019-0738-x.

38. Buckley, S.J. Ecstatic Birth: Nature's Hormonal Blueprint for Labor. E-Book; 2010;

39. Domańska, U.; Ossowski, R.; Ciżkowicz, B. Psychological and Socio-Demographic Correlates of Women's Decisions to Give Birth at Home. 2014, doi:10.5114/HPR.2014.45156. 